\title{
Do espaço sagrado à pista de dança: o caso das igrejas medievais de Norwich
}

From sacred place to dancing venue: the medieval churches in Norwich

Luís Mauro Sá MARTINO•

Resumo: Este texto mostra os efeitos do processo de secularização na conversão de espaços religiosos em lugares laicos. O estudo de caso foca as construções religiosas medievais da cidade de Norwich, Inglaterra, que deixaram de ser usadas para a prática religiosa. A partir de pesquisa de campo e análise documental, é possível notar três principais tipos de usos do antigo espaço religioso: a preservação integral, a locação para um uso que respeite o aspecto histórico e o abandono do lugar às necessidades de transformação.

Palavras-chave: Secularização; Arquitetura; Espaço.

Abstract: This article shows the effects of secularization process on religious spaces converted into lay places. The case study focuses on the redundant religious medieval buildings of Norwich, England. Field research and documental analysis shows that the secularization of places can assume three forms: the preservation of places intact as part of the historical legacy of an age; the lenting of the old buildings to a 'friendly' new use; finally, the scraping of any historical reference and the building use as any other.

Keywords: Secularization; Architecture; Place.

O conceito de "secularização" refere-se a uma gama variada de fenômenos sociais ocorridos em momentos diferentes na história ocidental. No entanto, parece haver algum consenso de que secularização remete à perda progressiva do espaço dos valores religiosos na sociedade (BERGER, 1987; WILSON, 1992; PIERUCCI, 1998). Se isso significa ou não um declínio da religião é uma discussão que faz correr rios de tinta na análise acadêmica (SOUZA, 1986; PIERUCCI, 1998; MARTIN, 1992; MORRIS, 2003). O objetivo deste texto é examinar um aspecto do processo de secularização: a transformação de lugares religiosos em espaços laicos e sua consequente alteração de uso e sentido.

De certa maneira, boa parte dos estudos sobre o declínio ou recuperação da religião na sociedade trata da secularização das práticas; neste texto, o foco é a secularização dos espaços. Essa perspectiva está ligada ao sentido original do conceito: "secularizar", área referia-se ao ato de transferir o controle de uma porção de terra da igreja para o Estado (HAMILTON, 1995; WILSON, 2003).

O caso estudado é a transformação das igrejas medievais da cidade de Norwich, na região de East Anglia, leste da Inglaterra, em centros de exposições, livrarias e museus. O caso é representativo no que se compreende como parte do processo de secularização dos espaços. O objeto se impõe também pela magnitude: Norwich possui a maior coleção de igrejas medievais da

\footnotetext{
- Professor Doutor - Faculdade Cásper Líbero - Av. Paulista, 900, CEP 01310-940, São Paulo, São Paulo, Brasil. E-mail: $\underline{\text { Imsamartino@uol.com.br }}$
} 
Inglaterra: são trinta e seis, das quais apenas três sobreviveram ao século XX mantendo atividades religiosas (MEERES, 1990). A ideia deste texto é identificar esse movimento como um exemplo de secularização do espaço.

Quando uma igreja não é mais necessária para uso religioso, por conta do baixo número de fiéis, a congregação ("parish") é reunida com a de outra igreja e o edifício é declarado "redundant", "desnecessário". Esse código indica que o espaço não é mais religioso. Esse fenômeno é pouco visto no Brasil: Em um país onde pululam novas igrejas a cada dia, e no qual cinemas e teatros são convertidos em templos de denominações religiosas, é raro observar a secularização dos espaços, conversão de um local de uso tradicionalmente consagrado à religião para outra atividade.

Antes de examinar a secularização contemporânea, cabe um breve exame das condições prévias de uso dos lugares e das alterações da situação jurídica dos edifícios em sua transformação de local sagrado em espaço laico.

\section{Alterações e mudanças anteriores ao século $\mathrm{XX}$}

Norwich é uma das cidades mais antigas da Inglaterra. Os primeiros indícios de povoamento remetem ainda à Britânia Romana, e foi também uma das primeiras regiões a ter uma população identificada como "anglos". A cidade também foi um dos teatros da invasão dos saxões, no século VI, dos ataques e assentamentos Vikings, durante os séculos VIII - X, e, finalmente, um dos palcos da invasão normanda de 1066. Arquitetonicamente, os edifícios, atualmente visíveis de todas as igrejas da cidade, datam desse último período (séculos XIII-XV), embora a maior parte tenha sido construída sobre o fundamento de igrejas anglo-saxãs anteriores (COOK, 1954; MEERES, 1990; KENT, SPENCER E COURT, 1990; WATKIN, 2005).

A primeira onda de secularização veio com a Reforma Anglicana, em 1538, que dissolveu os monastérios e eliminou das igrejas tudo o que remetesse à igreja Católica Romana. Isso significou a destruição de um sem-número de vitrais, imagens, pinturas, livros e outros materiais, algo que continuou no século seguinte durante o governo puritano de Oliver Cromwell. Como lembram Cook (1957) e Ruguin (1990), a consolidação da Igreja Anglicana no século XVII trouxe uma relativa acomodação a essas construções, mas, no século XIX, o chamado "Gothic Revival" ou "Victorian Gothic”, movimento artístico-literário ligado por intelectuais como August Pugin, Dante Gabriel Rosseti e John Ruskin gerou uma onda de "restaurações" nas igrejas medievais com o intuito de torná-las próximas do que teriam sido na Idade Média - mesmo quando isso significava destruir o pouco que sobrava de autenticamente medieval e construir algo novo no lugar, a partir do que se imaginava ser o original (COOK, 1954; 1957). 
No entanto, como lembram Lewis (2002) e Stancliffe (2008, p.219) essas alterações no espaço eram feitas no sentido de conservação do aspecto religioso, seja sob influência desta ou daquela corrente religiosa ou corrente estética. O "gothic revival”, por exemplo, esteve associado à tentativa de retomar, na igreja Anglicana, aspectos da liturgia católica pré-Reforma. As mudanças nos edifícios das igrejas, nesse momento, fundamentavam-se no que seria o retorno a uma Idade Média mais sonhada do que propriamente documentada.

O tipo de alteração que será estudado neste texto é de outra natureza: trata-se da alteração do status de um determinado espaço religioso para o nível laico e o que acontece com as construções medievais. A partir da questão do lugar e do uso do lugar, conforme explica Milton Santos (1996, p.71), nota-se a confluência de um problema sociológico, a secularização, visto em perspectiva histórica e com ênfase na alteração nos usos e significados do espaço físico/simbólico dessas igrejas.

\section{A secularização no século $X X$ : a situação jurídica}

Uma vez que o declínio no número de fiéis tornou as igrejas "redundant", o que deve ser feito delas? O valor imobiliário dos terrenos torna atrativo derrubar as construções para dar espaço a novos conjuntos comerciais - a maior parte das igrejas está na região central da cidade. Nesse momento, o elemento religioso se converte em uma questão vinculada à conservação da igreja não mais como espaço sagrado, mas como local histórico.

Na concepção de Durkheim (1994) e Elíade (1996), o sagrado se distingue do profano por conta de sua completa alteridade, pela demarcação visível do próximo (o comum) e do distante (o sagrado). É possível dizer que o uso dessas igrejas passa por uma alteração de valor: o sagrado, atribuído pela comunidade de fiéis ao edifício liturgicamente consagrado, confronta-se com o valor histórico de um lugar a ser preservado como parte da memória coletiva do país. A secularização do espaço litúrgico transforma-o em espaço de preservação histórica. No caso das igrejas medievais de Norwich, essa transformação pode ser acompanhada nos diversos tratamentos dados a cada uma das construções.

Usando uma distinção de Nora (1993), seria possível dizer que o processo de secularização transformou as igrejas de Norwich, antes "lugares de memória", em espaços da história: são arquivos de um período de florescimento econômico da cidade que durou do século XIII ao XVI. A problemática atual refere-se ao que fazer com esses arquivos, como conservá-los e a que preço. Além disso, trata-se de uma redefinição de identidade: na medida em que não fazem mais parte da memória como edifício sagrado, misturam-se à paisagem urbana conservados como documentos da história. 
Um primeiro elemento a destacar é a alteração na situação legal das igrejas: juridicamente, elas deixam de estar sob cuidado exclusivo da esfera de gestores dos bens simbólicos sagrados, a Diocese Anglicana de Norwich, e passam para associações laicas. O espaço deixa o domínio eclesiástico subordinado ao Estado (a rainha da Inglaterra é a chefe temporal da igreja anglicana) e passa à jurisdição da sociedade civil (TURNER, 2003) e, em alguns casos, para consórcios privados ou mesmo indivíduos.

Há duas entidades principais responsáveis pela preservação das igrejas. O "Norwich Historic Churches Trust" (NHCT), na esfera local, e o "The Church Consevation Trust" (TCCT), de alcance nacional. As áreas de atuação e objetivos de cada uma das entidades às vezes se sobrepõe e há divergências, sobretudo, no destino dado às construções. Grosso modo, enquanto o TCCT procura manter as igrejas tal como eram no momento em que se tornaram "redundant", conservando toda a mobília, os elementos litúrgicos e a decoração, o NHCT tem como objetivo encontrar um "uso amigável” para as igrejas, o que significa, na prática, alugá-las para outras atividades, que não impliquem dano à construção.

De acordo com o NHCT, o objetivo é tornar as construções lucrativas, de maneira a afastar qualquer moção no sentido de demolir os lugares. Já o TCCT entende que "preservar" é manter as características das igrejas intactas, o que nem sempre é possível já que, em alguns casos, a própria diocese anglicana de Norwich, ao declarar uma igreja "redundant", se encarrega de transferir a decoração interior para outros edifícios ainda em uso. No entanto, seja qual for o uso, é possível entender todo o processo como resultado da secularização, entendida aqui como o declínio da prática religiosa. Dessa maneira, cada uma das "redundant" acaba tendo um destino diferente conforme a negociação entre as três partes envolvidas. É possível, no entanto, identificar alguns casos representativos que podem ser exemplos dos destinos possíveis para as igrejas.

A construção dessa tipologia resulta, em primeiro lugar, de trabalho de campo realizado pelo autor durante o ano de 2008, quando foi possível visitar essas igrejas in loco e obter informações de primeira mão a respeito de seu uso e conservação. Esse trabalho sistemático de coleta de dados foi secundado pela análise de documentos a respeito de cada uma das igrejas - panfletos, sites, livretos de apresentação das comunidades - e de uma bibliografia específica a respeito do tema. A tipologia foi elaborada a partir de uma pergunta que orienta este texto: quais os usos do espaço litúrgico a partir do momento em que ele deixa de ser necessário à prática religiosa? A resposta permitiu identificar três principais usos, agrupados na tipologia mencionada.

Não se trata, aqui, de fazer uma tipologia completa dos resultados e efeitos da secularização sobre os edifícios religiosos, mas destacar alguns como sendo particularmente representativos do processo de transformação dos edifícios religiosos em espaços laicos. Entende-se que essa modificação resulta também do conflito entre as entidades de preservação, o valor dos terrenos e a 
Diocese Anglicana de Norwich. Não existe o dispositivo do "tombamento" estatal: a preservação, quando existe, é fruto de iniciativa da sociedade civil e entidades de conservação. De acordo com a dinâmica de forças entre esses três vetores, é possível identificar três principais tipos de uso secular das igrejas.

O primeiro é a preservação integral: após serem declaradas "redundant", as igrejas tornam-se locais históricos e não sofrem alterações; o segundo é o que se poderia chamar de "intermediário": desprovida de sua decoração interior e aparato litúrgico, procura-se uma articulação entre novos usos e a preservação do espaço no sentido de encontrar um uso "amigável” do espaço. Finalmente, a secularização radical: quando as construções são alugadas ou mesmo vendidas para particulares, que têm o direito de dispor dos edifícios como julgarem correto. Nesses casos, há uma eliminação de qualquer elemento sagrado residual, deixando o local pronto para uso como qualquer outro. Os dados e datas foram retirados especialmente de Kent, Spencer e Court (1990), Meeres (1990) e Knott (2009).

\section{A preservação integral}

O primeiro exemplo de preservação intacta é a igreja de St John Maddermarket. Os primeiros indícios de uma igreja naquela área data do período anglo-saxão, portanto, antes de 1066. A construção original foi substituída pela atual provavelmente no século XIV, quando a maior parte das igrejas de Norwich ganhou as formas e dimensões góticas que apresentam hoje. Na Reforma Anglicana o edifício simplesmente passou para o controle da nova denominação, sem que maiores alterações fossem feitas (DUFFY, 1992). O "gothic revival" do século 19 dotou a igreja de novos vitrais e de uma capela dedicada à Santa Maria. Foi declarada "redundant" para a igreja Anglicana em 1982. Sob os cuidados do TCCT, St John Maddermarket foi inteiramente conservada. A decoração interior, incluindo os elementos litúrgicos, são mantidos como se estivesse em funcionamento - velas são acesas diariamente pelo responsável pela igreja, Peter Ward, exprofessor da Universidade de East Anglia. Em St John Maddermarket a noção de "preservar" refere-se a congelar o tempo: não há alterações em nenhuma parte da construção, nem mesmo tentativas de reconstruir o que havia sido previamente destruído, alterações feitas até o século XX (KNOTT, 2009).

Outro exemplo de conservação in totum é a igreja de St Clemens. A construção atual data do século XIII, mas foi levantada sobre as fundações de uma igreja do período saxão de construção anterior - não há documentos a respeito do período exato. St Clemens foi declarada redundante em 1973, mas os elementos interiores foram rigorosamente preservados, incluíndo o órgão de tubos e a mobília, da época vitoriana. Os vitrais, destruídos durante a Reforma, não foram refeitos durante o 
"Gothic Revival”, que se limitou a reconstruir as janelas e fazer outras alterações menores. Também nas mãos do TCCT, St Clemens é aberta à visitação pública nos finais de semana e é preservada como documento histórico (TCCT, 2009; KNOTT, 2009).

A preservação da cultura material dessas duas igrejas permite a sua identificação como espaços sagrados: a presença dos objetos de culto, dos painéis e vitrais, mantém o que poderia ser chamado de um "ambiente sacro", mesmo que, teologicamente, essas duas igrejas não sejam mais consagradas. A distinção do espaço mantém o elemento de percepção do "sagrado" como algo distante (ELIADE, 1996; OTTO, 1992).

A escolha dessas duas igrejas para preservação integral aparentemente está ligada tanto às questões políticas quanto históricas. Nem St John Maddermarket nem St Clemens são escolhas evidentes, mesmo com esta última sendo lembrada como uma das mais antigas da cidade - há outras, datadas de época semelhante, completamente destruídas.

Aparentemente, não se trata de uma escolha, mas de preservar os lugares que não tinham sido destruídos. Alguns pesquisadores sugerem que os Conselhos de Conservação foram criados para preservar o que havia restado: como dito, ao serem declaradas "redundant", as igrejas eram simplesmente destituídas de toda decoração e mobília interna, e os rearranjos para outras atividades têm sido frequentes. Isso leva ao segundo tipo de uso das igrejas medievais, a proposta de preservação da carcaça do edifício, mas permitindo alterações internas.

\section{O modelo intermediário}

A igreja de St Michael-at-Plea, construída no século XV, tornou-se "redundant" no início dos anos 1970. Antes disso, havia sido reformada em pelo menos duas ocasiões, logo após a separação da igreja de Roma e no ano 1866. Desnecessária para cerimônias religiosas, foi despida de sua mobília eclesiástica e de seus elementos litúrgicos, tornou-se uma livraria especializada em literatura cristã - o Norwich Christian Resource Centre - e foi dotada de uma lanchonete, o Forgetme-not Café. Essas duas alterações provocaram uma mudança na estrutura da construção: para manter um café no qual se servem pratos quentes foi necessário criar uma abertura na parede de maneira a instalar uma chaminé. As lápides no chão e nas paredes foram cobertas por estantes de livros, carpetes e displays onde ficam os produtos à venda, sem mencionar as instalações elétricas necessárias para garantir o funcionamento de todo o conjunto. Conforme o panfleto de apresentação da igreja, procurou-se com tudo isso garantir um uso "cristão" do edifício, tornando-o autosustentável, eventualmente lucrativo. O objetivo, explica-se, era evitar um uso "que não estivesse de acordo" com a tradição do local. 
Algo semelhante acontece com a igreja de All Saints-at-Green Street. Construída originalmente no século XIV, reunia uma das menores congregações da cidade, ficando próxima de um dos portões de acesso. A igreja tornou-se "redundant" nos anos 1970, e desde então as entidades responsáveis pela preservação do patrimônio procuraram um uso "amigável” para o lugar. A solução foi transformá-la, assim como St Michael-at-Plea, em uma mistura de mercado, biblioteca e livraria de segunda mão, mantendo ainda um espaço para cerimônias religiosas, em uma espécie de bricolage pós-moderna de convivência entre o espaço sagrado e a atividade secular. A aglutinação é tanto mais radical do que em St Michael-at-Plea na medida em que não há descontinuidade entre os lugares. Embora a nave da igreja comporte atualmente uma lanchonete e um espaço para a venda de alimentos produzidos nas fazendas da região de Norfolk, de mesas e cadeiras à disposição do público, a capela - o "high altar" - é mantida intacta para pequenas cerimônias religiosas, além de comportar uma biblioteca circulante especializada em literatura cristã. Há uma espécie de justaposição dos tempos e dos espaços: desnecessário para as atividades litúrgicas, a igreja pode servir para outras finalidades; no entanto, não deixa de ser uma igreja, e essas finalidades não podem ultrapassar um limite, devendo conviver com o passado representado na biblioteca cristã e nas cerimônias oficiadas na capela (SPENCER, KENT E COURT, 1990; KNOTT, 2009).

Nos dois casos mencionados, o discurso de preservação de certa maneira choca-se com sua realização: conservar o local significa transformá-lo em algo lucrativo, adaptando-o às exigências da especulação imobiliária. A secularização, aqui, parece significar a rendição do espaço ao capital. Perdido o valor religioso do local, sua importância histórica foi igualmente deixada de lado em nome de sua transformação em fonte de renda, sob pena de, novamente, enfrentar ameaças de demolição por conta do valor do terreno.

O que acontece com St Michael-at-Plea e em All Saints Green pode ser considerado um modelo "intermediário" de secularização dos edifícios religiosos na medida em que procura-se garantir algum tipo de elo de ligação entre seu passado, como espaço sagrado cristão, e sua condição atual. A aproximação com o cotidiano é muito mais ampla do que nos dois casos previamente mencionados - não há o silêncio geralmente associado às igrejas como locais de oração, mas o ruído comum de uma livraria ou estabelecimento comercial.

Em termos de preservação histórica, no entanto, parece que o meio termo não é atingido pelo menos não conforme as intenções dispostas no discurso oficial - na medida em que apenas a parte externa da construção é mantida inalterada, e mudanças internas que implique a demolição do que foi feito também são proibidas. No entanto, a quantidade de modificações necessárias para abrigar outras atividades permite questionar até que ponto, de fato, o valor histórico do local é conservado. 
A esse modelo intermediário pode-se acrescentar um terceiro tipo, no qual a secularização do espaço é completa e, exceto pelo formato externo da construção, há poucos traços que permitam a identificação do lugar como uma igreja. Nesse terceiro caso, tanto o valor religioso do lugar quanto o valor de preservação histórica são deixados para trás em nome do ajuste do espaço às exigências contemporâneas.

\section{A secularização radical}

Os exemplos mais completos de secularização apontam para a eliminação dos elementos religiosos presentes nos edifícios litúrgicos. É nesse momento, talvez, que a noção de secularização fica mais explícita e é quando se pode falar então em uma completa transformação do espaço, que perde de vez suas características religiosas, exceto pelo formato externo e um ou outro detalhe preservado. É nesse sentido que, Inglaterra afora, é possível encontrar igrejas transformadas em teatros, cinemas, centros de exposições, albergues, lojas e até boates, danceterias e casas de espetáculos. Exemplos desse tipo existem em várias igrejas de Norwich, nas quais se pode observar a força do processo de secularização na conversão do espaço sagrado em território comum com o desligamento total de vínculos - os exemplos dessa natureza são os mais numerosos.

Na prática, isso implica a destruição completa não apenas do que seria a "atmosfera" religiosa do lugar, mas também dos elementos físicos - o que elimina completamente a distinção sagrado/profano mencionada anteriormente. A cultura material religiosa disposta nessas igrejas é destruída conforme a necessidade dos novos ocupantes, com uma perda irremediável de documentos históricos conservados na forma de lápides, monumentos, decoração interior, altares, vitrais e quaisquer outros elementos que permitam identificar o caráter religioso.

A destruição das igrejas provocada pela secularização, neste caso, não atende a nenhuma disposição de caráter doutrinário, mas às necessidades de implemento do edifício geradas pelo seu novo uso: assim, diante da necessidade de tornar o espaço lucrativo, deixa-se de lado qualquer movimento no sentido de preservar o espaço histórico representado pela cultura material religiosa. Nesse terceiro tipo de uso das igrejas medievais "redundant", secularizar significa adaptar às necessidades pragmáticas do ocupante, colocando em primeiro plano a reprodução e recuperação do capital investido na adequação dos edifícios às novas funções. $O$ que sobreviveu à Reforma Anglicana, à revolução puritana e à febre de restauração do "Victorian gothic", parece ser finalmente destruído pelas formas de transformação perpetradas pelo capital: nas igrejas onde se pode identificar essa secularização radical, o espaço torna-se meio de produção.

Construída sobre as fundações de uma antiga igreja do período saxão, St Martin-at-PalacePlain, é hoje um centro de triagem do Serviço Social Britânico. O interior da construção foi dividido 
com placas de fórmica separando as diversas funções burocráticas. Escadas, salas, instalações elétricas e de aquecimento foram acrescentados ao local, hoje uma espécie de repartição pública. Para isso, foram destruídas dezenas de lápides e urnas funerárias, a maior parte delas datando do século XVIII, sobre as quais era possível ler últimas vontades, testamentos e indícios da longevidade da população. Pode-se advinhar a extensão do trabalho de destruição pelas lápides restantes: algumas estacas, paredes e divisórias foram fixadas sobre as pedras tumulares, deixandoas parcialmente visíveis. O interior da construção foi completamente pintado, cobrindo inscrições e o que havia sobrevivido de um mural medieval. Os únicos elementos restantes foram o túmulo de uma personagem importante na história da cidade e uma pintura feita na época do "gothic revival" sobre a porta de entrada do norte da construção. Trata-se de uma inscrição, provavelmente feita para a reinauguração da igreja no século XIX, após sua restauração: "How dreadful is this place. This is none other than the House of God, and these are the gates of Heaven”. O restante da construção é um moderno conjunto de escritórios.

A igreja de St Margaret, em Benedict Street, foi completamente destituída de todos os elementos religiosos e o espaço hoje é usado como galeria de arte e centro de exposições. Exceto dois vitrais da época vitoriana e três pedras tumulares, nada mais foi preservado. $\mathrm{O}$ espaço, completamente vazio, abriga também feiras de roupas, exposições diversas e chegou a sediar uma convenção de fabricantes de chocolate em 2008. Construída por algumas das mais ricas famílias da Norwich medieval, St Margaret tornou-se "redundant" em meados dos anos 1970, e passou um longo tempo fechada antes de ser reaberta como um centro de artes, já nos anos 2000. Atualmente, está sob conservação do TCCT, mas, por conta de questões burocráticas e judiciais, os locatários têm completa autonomia para fazer o que julgarem necessário com a construção, incluindo alterações em sua estrutura interna - a instalação de geradores de energia elétrica é o elemento mais recente nesse sentido.

Finalmente, outro caso radical de alteração nos usos e sentidos do espaço pode ser localizado na igreja de St Swithin, a um quarteirão de St Margaret. Após a Reforma Anglicana, quando a igreja foi destituída de todos os elementos católicos romanos, o edifício sobreviveu em condições difíceis até meados do século XX - já no final do século XIX sua torre estava em situação tão precária que foi demolida e substituída por um pequeno campanário ("turret”) no alto da nave principal. Tornada "redundant" nos anos 1970, foi transformada em 1998 no Norwich Arts Centre. Atualmente, é uma das principais casas noturnas da cidade, abrigando desde shows de rock and roll até exposições de arte contemporânea. Além disso, há uma feira permanente de artesanato, roupas e outros objetos. Para abrigar esses eventos, o plano arquitetônico do edifício foi alterado: um pavilhão de aço, com cobertura de telhas plásticas, foi acoplado ao pórtico leste da igreja, onde ficava o antigo altar. Com isso, uma das características principais das igrejas medievais da cidade, o altar voltado para o leste, 
foi perdida. O interior de St Swithin é construído como um teatro: nada há que lembre o uso litúrgico anterior - todo o assoalho, bem como as paredes, são contemporâneos, e não existem sinais das lápides, nem das urnas funerárias, nem dos brasões memorais que costumam decorar as paredes das igrejas. Exceto por uma porção do aspecto exterior, distante da nova construção, seria difícil identificá-la como uma igreja medieval. O Norwich Arts Centre é tido em alta conta pela imprensa local, mas nenhuma menção é feita ao passado histórico: apenas a utilização presente é destacada por conta das apresentações realizadas lá.

Destituída de signos, a igreja medieval perde completamente seu significado original e, de certa maneira, até mesmo de seu sentido histórico na medida em que não resta senão a documentação do passado (GRANT, 2005). Como documento histórico, a construção deixa de existir.

\section{Considerações finais}

Milton Santos (1985; 1996, p.49-70) explica que os usos de um espaço estão ligados diretamente aos significados atribuídos a ele. A dimensão simbólica dos espaços sociais gravita também pela geografia dos sentidos nos lugares. Dessa maneira, compreender o processo de secularização a partir das transformações do espaço permite observar em que proporção, de fato, há uma mudança no sentido atribuído a ele (FERRARA, 2001, p.38).

Neste texto, foi possível pontuar três principais usos das igrejas medievais de Norwich após serem declaradas desnecessárias para uso litúrgico - a tentativa de preservação da memória histórica, a adequação às outras utilidades ligadas, ao menos no discurso, com algo relacionado à religião e, finalmente, a alteração radical do espaço. A paisagem de Norwich é pontuada pelas torres das igrejas medievais, documentos de uma época, os século XIV à XVI, quando a cidade era a segunda mais rica da Inglaterra, perdendo apenas para Londres. Atualmente, essas igrejas, vazias, indicam o curso de um processo de secularização que redefine os espaços, alterando também os significados de cada espaço (SANTOS, 1985).

Nesse sentido, o declínio da religião pode ser mensurado na transformação dos lugares litúrgicos em espaços laicos sem nenhum tipo de recrudescimento em outra parte. E, nesse instante, o problema da secularização encontra-se com a questão da preservação histórica, perguntando-se, qual o sentido de manter um espaço por seu valor histórico quando o valor de uso do terreno seria certamente maior? (BOLLE, 1970). O simbólico, nesse caso, entra como instrumento de troca: a secularização, em última instância, significa a adequação do sentido da história na lógica de mercado. 


\section{Agradecimentos}

O autor agradece a leitura do Prof. Dr. José Augusto Dias Jr à primeira versão deste texto.

\section{Referências Bibliográficas}

BERGER, P. The Social Construction of Religion. Londres: Penguin, 1987.

BOLLE, K. Secularization as a Problem for the History of Religions. Comparative Studies in Society and History, v.12, n. 3. (Jul. 1970), pp. 242-259, 1970.

BRUCE, S. "The Pervasive World-View: Religion in Pre-Modern Britain" The British Journal of Sociology, v. 48, n. 4 (Dec., 1997), pp. 667-680, 1997.

COOK, G. H. The English mediaeval parish church. Londres: Phoenix, 1954.

. The English cathedral through the ages. Londres: Phoenix, 1957.

DURKHEIM, É. As Formas Elementares da Vida Religiosa. São Paulo: Martins Fontes, 1996.

FERRARA, L. A. Leitura sem palavras. São Paulo: Ática, 2001.

GRANT, D. S. Symbols, stories, and practices. The Sociological Quarterly, v.42, n.2, pp233-251, 2005.

HAMILTON, M. The sociology of religion. London: Routledge, 1995.

KNOTT, S. Norfolk Churches. < $\underline{\text { http://www.norfolkchurches.co.uk> }}$. Acesso em 25/07/2009.

LEWIS, M. The Gothic Revival. Londres: Thames \& Hudson, 2002.

MARTI, O. Economic Factors Tending Toward Secularization of Church Property in England, 1533-39. The Journal of Political Economy, v.37, n.4, Aug., 1929.

MARTIN, D. The Secularization Issue: Prospect and Retrospect. The British Journal of Sociology, v. 42, n.3. (Sep., 1991), pp. 465-474, 1991.

. The Sociology of Religion: A Case of Status Deprivation? The British Journal of Sociology, v.17, n. 4. (Dec., 1966), pp. 353-359, 1966.

MEERES, F. A history of Norwich. Londres: Phillimore \& Co Ltd, 1990.

MORRIS, J. The Strange Death of Christian Britain: Another Look at the Secularization Debate. The Historical Journal, v. 46, n. 4 (Dec., 2003), pp. 963-976, 2003.

NORA, P. Entre memória e história: a problemática dos lugares. Projeto História, n.10, Dezembro 1993, pp. 7-28.

NORWICH CONSERVATION CHURCHES TRUST. The Work of NCCT. $<$ http://www.norwichchurches.org/about/about nhct.shtm>. Acesso em 28/07/2009. 
PFAUTZ, H. The Sociology of Secularization: Religious Groups. The American Journal of Sociology, v. 61, n. 2 (Sep., 1955), pp. 121-128, 1955.

PIERUCCI, A. F. Reencantamento e secularização. Novos Estudos CEBRAP, n.49, julho 1998.

RAGUIN, V. Revivals, Revivalists, and Architectural Stained Glass. The Journal of the Society of Architectural Historians, v.49, n.3 (Sep., 1990), pp. 310-329, 1990.

SANTOS, M. Técnica Espaço Tempo. São Paulo: Hucitec, 1996.

. Espaço e Método. São Paulo: Nobel, 1985.

SOUZA, L . A. Secularização em declínio e potencialidade transformadora do sagrado. Religião e Sociedade, Rio de Janeiro, ISER, 13(2), 1986.

SPENCER, N., KENT, D. e COURT, A. The old churches of Norwich. Norwich, Jarrold Publishing, 1990.

STANCLIFFE, D. Church Architecture. Londres: Lion, 2008.

THE CHURCH CONSERVATION TRUST. The trust.

$<$ http://www.visitchurches.org.uk/thetrust/>. Acesso em 28/07/2009

TURNER, B. Law and religion. Theory, Culture \& Society 23(2-3), 2003.

WILSON, B. Religion in sociological perspective, Oxford: Oxford Press, 1982.

WATKIN, D. English Architecture. Londres: Thames \& Hudson, 2005.

Artigo recebido em 10/2009. Aprovado em 11/2009. 